\title{
DIGITAL MEDIA ETHICS
}

\section{Aleš ROZEHNAL ${ }^{1}$}

This paper provides an understanding of immediate and interactive standards of media ethics that should be applied to digital media. Digital media are partly based on amateur journalism, and most principles of media ethics were developed over the last century. The question then is whether it is possible to create media ethics whose standards apply to social and traditional media platforms or whether we will have different standards for different media platforms.

\begin{tabular}{l|l} 
digital media \\
media ethics \\
freedom of speech \\
protection of personality \\
proof of truth
\end{tabular}

\section{Introduction}

The media is an indispensable part of a democratic society. Protecting freedom of expression creates a marketplace for ideas and allows citizens to hold public officials and public figures accountable for their actions.

However, protecting the freedom of expression does not automatically imply the media's credibility, which depends largely on strict adherence to ethical practices.

The media revolution is fundamentally and irreversibly changing the nature of journalism and ethics. The means of publishing are now in the hands of citizens, and the Internet is supporting new forms of journalism that are interactive and immediate.

The main question is to what extent the existing media ethics are appropriate for the current form of news, which is immediate and interactive. Moreover, this is amateur journalism. However, most of the principles of media ethics have developed over the last century.

One of the media ethics issues mentioned above is whether ethical standards should apply to all media types, for example, whether social media should be balanced and impartial.

1 | Associate Professor, Faculty of Law, Charles University, Prague, the Czech Republic, rozehnal@ ak-rozehnal.cz. 
The media are increasingly able to engage with citizens in reporting social events. This raises related questions about how sources should be identified, how much verification is necessary for different types of news, or whether citizen contributors should be made aware of editorial standards.

The question then is whether it is possible to create media ethics whose standards apply to social and traditional media platforms or whether we will have different standards for different media platforms.

\section{Media landscape}

Media's words are moving toward a mixed type of media: citizen and professional journalism across many media platforms. Tension exists between traditional media and citizen journalism. The traditional journalism values are accuracy, verification, and impartiality, whereas citizen journalism (social media) values are immediacy, transparency, and strong opinions.

News and images circulate the world at a tremendous speed via Twitter, YouTube, Facebook, blogs, and emails. The speed puts pressure on media to publish news before it is sufficiently verified, which often leads to picking up news from social media.

Activist journalism likes to comment on events and issues without verification. Traditional media are increasingly being forced to move towards a more opinionated approach to news and commentary. This is because being impartial is boring for the recipients of media content, as they are attracted to strong opinions and clashes of opinion.

\section{The objectivity of the media}

By their very nature, the media and journalists are not only mediators of information between the world of politics and the public, but they also interpret and rank events and disseminate their opinions, thereby influencing the political agenda and public opinion.

The fact is not in itself contrary to the requirement of objectivity and balance but is immanent to the media. It is through editorial policy that the media establish themselves in the media market and position themselves among a certain political segment of the public ${ }^{2}$.

The objectivity and balance are not unbiased. The objectivity and balance of the media and journalists cannot simply present opposing views because such an approach would lead to imbalance ${ }^{3}$.

For example, the views of both the lawbreaker and the victim of the lawbreaking, or the supporter of freedom and democracy and the one who wants to destroy freedom and democracy, would be presented as equal. However, such a conclusion is unacceptable because it would lead to a trampling of the values on which our society is based.

2 | Burton and Jirák, 2001.

3 | Rozehnal, 2015. 
Therefore, the media's task is not to provide coverage that is free of any opinion but to ensure that those opinions are as diverse as possible if they are in the field of the values that underpin the political, legal, and social structures of democratic societies: respect for human rights, culture, and political pluralism ${ }^{4}$.

A form of journalism in which the journalist tries to balance two opposing sides often leads to an inaccurate result because one side may be right and the other may not. Journalism is either good or bad, regardless of whether it is opinionated. The real test of the quality of journalism is not whether a journalist has an opinion but whether the reporting is supported by a correct assessment of the facts.

Many media platforms require their journalists to use social media to gather information on social media and start their own blogs, Facebook pages, or Twitter accounts. However, the media have the responsibility not to contribute to the amount of fake news circulating in cyberspace. By forwarding or publishing information of someone else, the media are a guarantor of the truth of that information.

At a time when media are often accused of spreading fake news, it is crucial that when journalists use platforms such as social media, chat rooms, and forums for their reporting, they verify their sources and information from these sites.

It is in the interest of freedom of political debate for a journalist to express critical and provocative views and not just make neutral rejoinder recordings. The media are not obliged to be morally or politically neutral.

Nevertheless, the goal of all media, even digital media, should be impartiality and objectivity. Impartiality refers to accuracy, fairness, respect for the truth and cannot be equated with mere mathematical time budgeting.

News and criticism, that is, evaluative comments, are often mixed. Information in articles, headlines, and news is usually assertions, while opinions published in materials that are evaluative or subjective are usually criticized.

Criticism is less likely to affect a person's honor and dignity because its recipients do not take it as the sacred truth. However, even criticism must have a factual basis. This factual basis must be discernible to the recipient, even though all the facts may not be mentioned in the article or post. However, no criticism is defensible without the truth of the allegations.

Balance and equal access to the media cannot be understood mechanically as the absolute equality of subjects but in terms of graded equality. This means that each person must be given at least a minimum level of opportunity to present themselves in such a way as to meet the requirement of a plurality. However, beyond this minimum level, the representation of the subjects in the media must be commensurate with their political and social importance ${ }^{5}$.

The media would be violating the principle of balance and objectivity if they are found to commit the following:

I If a news report contains information out of context

I If a news report arranges the information in order of purpose and in a way that makes it sound entirely purposeful according to the commentary on the report

I If the media do not give the reported person the opportunity to express their views

I If such a statement is inadequate

4 | Drgonec, 2013.

5 | Decision of High Administrative Court, SJS 946/2006, Vol.15/2006. 
The legal concept of objectivity must be seen through the lens of the thesis "audiatur et altera pars" (let the other side be heard) for the assessment of disputes and the sense of objectivity on the parties ${ }^{6}$.

Of course, the principles given to judicial proceedings cannot be entirely copied in the media, but this principle must be applied. However, it is not possible to publish two contradictory opinions without further comments or explanations.

The principle of objectivity and balance must not be interpreted as a command to present only colorless, cautious, and hyper-correct opinions.

Therefore, the content of the media should be organized in such a way that individual contributions are often engaged, critical, and opinionated, while maintaining objectivity and truthfulness in the reporting of facts, but in their totality, forming a varied and representative mix of the spectrum of opinion in society, encouraging the widest and most open discussion of socially relevant topics ${ }^{7}$.

Objectivity can be characterized as neutrality in relation to the subject matter of the news, impartiality, truthfulness, and relevance. Balance can then be characterized as a balance in the proportions of the news or information conveyed.

The notion of objectivity, therefore, includes accuracy (precision), transparency (citation of sources), and factuality (absence of self-assessment). Balance is then impartiality, where some views are not suppressed in favor of others. It is questionable whether this quality can be conceptually attributed to information.

Only relevant information to the event being reported, including consideration of the context of the event, is objective and balanced. Therefore, it can be concluded that objective and balanced information is relevant information ${ }^{8}$.

The obligation to provide objective information necessary for the free formation of opinions must therefore be interpreted as an obligation to respect the principles of objectivity.

Certain media fall outside the objective and balanced criteria, such as entertainment, sports, children, and similar media. The role of the media is not to provide sterile information but to reflect reality, including the controversies, ambiguities, layers, and emotions it contains, as well as to provoke society-wide discussions on topical issues.

If the media is to meet the requirements of objectivity and balance, the relevant information must be presented in an unbiased form within that part of the media that forms a separate and separable entity from the other parts of the media dealing with a particular topic ${ }^{9}$.

The objectivity and balance of the media content must be seen as a whole since it also has an impact on the public as a whole ${ }^{10}$. Similarly, it is irrelevant that information on the matter was subsequently published, which contained the other party's views or supplemented the original communication. A later publication necessarily reaches a different type of recipient than the original information and is not capable of setting the record straight.

6 | Rozehnal, 2015.

7 | Decision of High Administrative Court, dated 5. 5. 2010, č.j. 7 As 23/2010-73.

8 | Decision of High Administrative Court dated 9. 9. 2011, čj. 7 As 2/2010-126.

9 | Decision of High Administrative Court dated 30. 5. 2008, č. j. 7 As 38/2007 - 78.

10 | Decision of High Administrative Court dated 27.1. 2010, č.j. 8 As 61/2009 - 61. 
No format allows a detailed description of the subject matter in a small space, but it is not possible to depart from the requirement that basic objective information be included in the media to form at least a basic idea of the position of the various bodies concerned ${ }^{11}$.

Therefore, it is not possible to publish a contribution, which is not based on the principle of objectivity and balance, on the grounds that this principle has been fulfilled by the subsequent publication of a similar contribution elsewhere. Such reporting is based on the choice. The time for a news report is limited, as is the space for news, even in digital media. By selecting only the (from their standpoint) important or interesting news from the daily portion of the world, domestic, and local news, the editorial staff makes such news biased.

However, objectivity, in this case, cannot be considered a philosophical term. This selection should be balanced, impartial, informed, and fair to be considered objective. This can be summarized as follows:

I objectivity of the separation of facts from opinions

I a balanced record and description of the debate

I confirmation of journalistic statements by reference to relevant authorities

The separation of facts from opinions cannot be understood as a demand to discard the journalist's own opinions. When they are expected to do so (columns, commentaries), journalists can express their opinions and feelings. However, it must be clear briefly that it is an opinion rather than a fact.

A balanced record can only be achieved through a kind of disembodiment of journalists. There must be no favor of their own assessment of the situation or the protagonists involved. The ability to let the representatives of the parties to the dispute speak and to give them equal space to express themselves, if possible, is also essential. All statements must be based on facts that are demonstrably independent of the media. In no case, can fabricated facts and evidence be accepted.

These rules can be applied to the so-called pyramid structure of a classic journalistic narrative. The point is that the news is sought out, reported, and interpreted. Under the term impartiality, a set of activities can be found, leading to the fact that no one current of opinion, thought, or art is favored over others.

\section{Social media manipulation}

Digital media use traffic as the only measure of quality. Unfortunately, this trend often leads to the creation of artificially exaggerated facts, where reality is altered to make the resulting message as sensational as possible, that is, to appeal to the widest possible audience. Journalists also make cultural assumptions about their work and use them to assess the credibility of their sources. The point is that whoever belongs to the elite (financial or political) is often judged as a more reliable source.

In the media, we encounter different types of manipulation. A common one is the manipulation of incomprehensibility. Information is full of incomprehensible and technical terms; sentences are usually very long. 
Often, the author has nothing to say but does not want the readers or viewers to know it, or they are just communicating banalities wrapped in technical language. Commercial media often use manipulation by overwhelming meaninglessness or manipulating emotions. Unfortunately, serious media do not avoid manipulation by selecting or ignoring news, ranking news, or choosing commentators.

We also often encounter the technique of argumentation and apparent logic, which presents logic on the recipient's side. The recipient then has the impression that they are the originator of the judgments, attitudes, and conclusions, without realizing that they are the tool of the real originator - the manipulator.

The technique of argumentation and apparent logic can make use of black and white argumentation. Manipulation and misinformation are sometimes based on argumentation by the absence of evidence ("nothing else has been proved"), argumentation by the crowd ("millions of people agree with this view") or argumentation by authority.

\section{Protection of personality}

Among the methods by which at least an approximate balance can be achieved are accuracy, clarity, and completeness of reporting, distance from the subject matter, discrimination-free access to sources of information, conscious neutrality in a multi-group dispute, the plurality of published opinions, exclusion of ulterior motives even in the absence of bona fide bias against large advertisers, an unequivocal prohibition on interfering with the fact being reported, and strict adherence to terminological neutrality.

Failure to comply with the principles of objectivity, balance, and impartiality may interfere with the right to protect personality. The right to the protection of personality is a general personality right since it belongs to every natural person as an individual. Its object is the intangible value of the human personality. Within this general personality right, there are an unlimited number of sub-rights of personality, such as the right to honor and human dignity, the right to personal privacy, the right to reputation, and the right to self-image.

Personality manifests itself as a dynamic system whose traits change with age, reaching relatively greater stability in adulthood. Personality is, among other things, a product of its time and its conditions, and at the same time, it shapes and reshapes its environment to one degree or another.

The physical components of a natural person's personality, such as his or her level of health, the peculiarities resulting from his or her individual appearance and physique, membership of the male or female population, a particular human race, etc., cannot be overlooked.

Despite the multiplicity of individual components and aspects of personality, the personality of a natural person must always be perceived in its integrity and indivisibility. The diversity of manifestations of the individual aspects of a natural person's human personality corresponds to the conceivably wide range of possible unjustified interference against any of these personality components.

Nevertheless, it is always the personality of the natural person as a totality of the characteristics and qualities that will be directly affected by such interference. Since it is the most private, innermost, and most intimate sphere of the human person, whose 
external interference is very often felt by a natural person with considerable adverse intensity, it is undoubtedly a matter for the law to provide appropriate legal protection to this personality sphere.

Within this unified framework of the right to the protection of personality, there are individual sub-rights that ensure the civil protection of individual values (aspects) of the personality of the natural person as an inseparable part of the overall physical and psychological-moral integrity of the personality.

The enumeration of these individual rights can be set as merely demonstrative. To establish a violation of the right to the protection of personality does not require a harmful consequence, but a mere threat to the rights of the person. Interference with the right to protection of personality may also occur without faults, that is, objectively, where the fault of the infringer is not required.

However, there must be a causal link between the interference with the right to the protection of personality and the violation of personality rights. The interference must exceed a certain level of intensity that can no longer be tolerated in a democratic society.

It is within the scope of the right to honor and dignity to prevent conduct that is objectively capable of causing harm by lowering the honor or dignity of a natural person in the eyes of others and thereby jeopardizing the esteem of his position and position in society.

Violations of the right to honor are generally committed by false factual allegations. However, the right to honor may also be infringed by true statements of fact if they are made in such a form or such a context or under such circumstances regarded as defamatory. A more difficult question is the admissibility of false statements where they are satire or parody, which serve to ridicule or ironize certain personal characteristics of public figures.

In this case, a reasonable recipient must recognize that these are fictitious and frivolous claims. If such a fact is apparent to the average reasonable citizen, there is no violation of the right to the protection of personality.

The reputation of an individual is a part of their personal and psychological identity. Reputation is what others think of the individual and not what the individual thinks of themselves. The law must protect reputation against extensive criticism, even if it is of public interest.

It is also not possible to justify a particular (albeit true) statement by false, misrepresentative, defamatory, or disparaging statements. It is not required that the person attacked be named in the offensive speech; identifying features that are sufficient to establish the identity of the person are sufficient.

However, if the statements are true and have a defamatory effect, but the person concerned has brought about the lowering of their honor and dignity by their own conduct, which is contrary to legal, moral, professional, or other generally accepted norms, this constitutes a permissible interference with personality rights.

The truth of such allegations must be proved by the person who has infringed on the honor of another by making the defamatory allegation. This reversal of the burden of proof is called proof of truth. The proof of truth needs not be complete, and may be only a partial truth ${ }^{12}$. 
The mere publication of a false statement affecting the personality of a natural person generally constitutes an unjustified interference with the right to the protection of their personality. The use of criticism, irony, condemnation, and repudiation of a natural person's actions or activities based on the circumstances in which false information is communicated generally constitutes a tangible unjustified interference with the natural person's right to protect their personality. The intensity of unjustified interference is considerable and will usually have adverse consequences for the person concerned in terms of their position in the family and society.

The proof of truth does not apply to allegations concerning private life. It is irrelevant whether such allegations are true or false, and it is even irrelevant whether they are defamatory. Such an interference is generally prohibited. It is also irrelevant whether the intruder intended to interfere with their honor and dignity.

What is decisive is whether the conduct in question is objectively capable of lowering honor and human dignity. Given that culpability in this offense is based on an objective principle, it is also irrelevant whether the person who violated the honor and dignity of a natural person had a good faith belief that the allegations were true. Thus, it is not possible, for example, to exclude the liability of a media outlet that has received certain false statements from a news agency.

Given the absolute responsibility for their content, the media may unjustifiably infringe the honor and dignity of a natural person by publishing defamatory factual statements (in particular, by publishing false facts).

The media cannot absolve themselves of their responsibility for interference with the right to protect a citizen's personality by pointing out that the author of the defamatory statements who published them in the media is a person different from the media and their editor - the author of the report.

The media's liability is not excluded if the report (article) contains a quotation from a third party, which is defamatory. It is irrelevant that the publisher, when publishing any defamatory information or unjustified criticism, also states that it does not express the opinion of the editorial staff or that it uses direct speech by the author of the defamatory information or unjustified criticism. However, this distinction can only be decisive in determining the amount or level of appropriate compensation.

Where a published interview is liable to interfere with the personality of a natural person, it cannot be held that, if the publisher has accurately reproduced the statements of the interviewee, they are only fulfilling their duty to inform the public and cannot be held liable for them. In the course of an interview, questions are deliberately asked about the interests of the media's journalistic purpose arising from the subject matter.

It cannot, therefore, be assumed that, without more, such cases are merely a reproduction of a person's statements. However, the fact of the journalistic cooperation of the media outlet or its staff and their contribution to the content and tone of the interview, or their influence on whether the interview is published must also be considered.

The degree of responsibility of the media depends on the source of the statement. Thus, a different degree of liability is imposed if the statement is made by a news agency or a spokesperson for a public authority, and a different degree of liability will be imposed if it is the opinion of a third party.

Another exception is so-called 'neutral reporting,' where the media merely repeat defamations made in a debate unless they accept them as truth. 
Similarly, it is not possible to relieve oneself of liability by introducing a statement with the phrase that such a fact is 'common knowledge,' 'widely reported,' 'it has long been circulating on an unofficial list,' and 'such reports are circulating from all quarters.' Again, it depends entirely on whether the allegation is true.

It is also undecidable as to the circle of persons into whose sphere the allegation has been made, by which, for example, dishonest conduct is alleged against a citizen. It is an allegation that is objectively capable of causing harm to citizens' rights to honor and dignity. An allegation that is said to have infringed a person's right to honor, and dignity must be examined as a whole, without being satisfied merely with an examination of whether individual sections, sentences, or words of the report are offensive. It is not sufficient to examine whether the offensive nature of the allegations is found in the individual sections or sentences of the report, or even in the individual words.

Words or phrases that are prima facie offensive may, when viewed in light of the content and meaning of the message as a whole, be devoid of that offensive character. However, words or phrases that are not offensive in themselves, when viewed in the light of the content and meaning of the message as a whole, may constitute the most serious and tangible infringement of personality rights ${ }^{13}$.

The honor of a natural person may be unjustifiably affected not only by publishing defamatory factual statements (in particular by publishing false facts) concerning the natural person but also by publishing inadmissible evaluative judgments about the natural person (inadmissible criticism of the citizen or his actions).

As a rule, criticism of a natural person's actions based on circumstances in which a true statement is made (unless the statement concerns an intimate aspect of the natural person's life) cannot be regarded as a violation of personality rights, even if the criticism uses a corresponding degree of irony, condemnation, and rejection of the criticized action of the natural person.

Legitimate criticism must first be based on true initial premises and logically derive the corresponding evaluative judgments from them. At the same time, the criticism must be specific and must not contain only general judgments (e.g., stating that a certain entrepreneur is incompetent, a certain decision is incompetent, etc.).

If the criticism uses expressions to characterize certain phenomena and persons (their actions and characteristics), the degree of expressiveness of which is out of proportion to the aim of the criticism, and this aim could have been achieved without such expressions, which implies an intention to offend the person criticized, it is disproportionate criticism that is capable of interfering with the right to protect the personality of the individual (sometimes termed 'intense excess').

The specificity of the interference with the right to honor by inadmissible criticism is that criticism, as a certain sum of evaluative judgments, always expresses the opinion of the person making such judgments. All criticisms are therefore subjective in nature and cannot be subjected to standards of truth or objective correctness. Proving the truth of an evaluative judgment undermines the freedom of expression ${ }^{14}$.

Criticism may be exaggerated, unreasonable and biased, provided that it is not motivated by malice. Unjustified criticism that does not go beyond the limits of criticism on the merits, based on the true facts and the conclusions drawn from them that justify 
those facts, and which is appropriate in content and form (it therefore also depends on the description of the individual phenomena, the form of the description of the citizen's conduct and the form of the characterization of its nature and characteristics) is permitted. Regarding the form of criticism (in particular, the terms and wording used), it cannot be considered in isolation or in the abstract from the content of the critical work.

From the standpoint of the adequacy of the criticism, it is, therefore, necessary to examine the proportion between the formal expressions contained in it, that is to say, the proportion of the means of criticism and the aim of the criticism, which is the socially approvable aim that the critic wishes to achieve by his assessment. Sometimes, to achieve the purpose of the criticism, for example, to arouse public interest in a particular serious social phenomenon, it is appropriate to use relatively "harsher" expressions, that might otherwise be considered offensive (e.g., in ordinary conversation).

Requiring that all terms used to describe specific phenomena or persons be moderate would, to the detriment of the cause, deprive criticism of a certain emotional charge that is often justified. In the case of criticism, proof of truth is excluded from the logic of the matter ${ }^{15}$. Legitimate criticism does not serve to insult or defame a person but to evaluate him, even if subjectively. Nor is it permissible for unjustified interference with honor and human dignity by insulting and disparaging statements to be justified on the grounds that certain statements are merely retaliation for previous statements made by the victim. Such a fact does not justify or outweigh the fact that the allegations are insulting and dehumanizing to another person. The right to express an opinion on allegations that are deemed to be false cannot be exercised in a manner that manifestly exceeds the bounds of decency ${ }^{16}$.

\section{Freedom of expression}

One of the limits of freedom of expression is the conflict between the right and the right to protect general personality rights. In media law, it is said with some exaggeration that the greater the truth that is published, the greater the defamation. Reporting in all forms of media involves the acquisition, classification, and presentation of current events in the form of news and involves a critical evaluation of the news ${ }^{17}$.

The goal of the media is, among other things, to inform the public about matters of legitimate public interest and to critically evaluate them, which is one of the main features of freedom of expression and the right to information, and therefore of the development of democracy and the control of political power ${ }^{18}$.

The media will always stand at the opposite pole of the protection of personality since much of the news media reports critically on certain individuals whose personality rights are thereby infringed. Given this antagonism, it is important to strike a balance between the opposite poles.

15 | ECHR, Lingens, 8. 7.1986, 1 - 103, Oberschlick, 26. 4.1995, A - 313.

16 | Decision of Constitutional Court dated 1.12. 2005 II. ÚS 94/05.

17 | Crone, 2002.

18| McLuhan, 2003. 
When the fundamental political right to information and its dissemination clashes with the right to protection of personality and private life, fundamental rights that are on the same footing, it will always be for the independent courts to consider carefully, taking into account the circumstances of each case, whether one right has been unjustifiably given priority over the other.

The form of the interference with personality rights, its scope, and its method, must always be appropriate to the purpose and, in any such application, the human dignity of the natural person concerned must always be respected; otherwise, it constitutes an unjustified interference with the personality of the natural person.

Another source of problems is the constant acceleration of the movement of information and its high demand. The basic criterion of news should be its truthfulness, objectivity, and balance, but at the same time, its timeliness, that is, the speed with which news is transmitted from the media to its recipients.

Certain features of the mainstream media intended to inform the general public (as opposed to, for example, specialist publications) must be respected. In certain cases, particularly given the scale of individual contributions and the interest of the readership, certain simplifications must be made.

Therefore, it cannot be argued without further ado that any simplification (or distortion) must necessarily lead to an infringement of the personality rights of the persons concerned. It is difficult to insist on the absolute accuracy of factual allegations and make demands on journalists that are-in their consequences-impossible to meet. Thus, the overall message of the information in question must correspond to the truth.

To assess whether the right to honor and human dignity have been violated, the information in question should be examined in the following ten aspects:

(1) The seriousness of the attack, bearing in mind that the more serious the untruthful attack on honor and dignity, the more the public is misinformed.

(2) The nature of the information and the extent to which it is a matter of public interest.

(3) The source of the information, particularly regarding whether the sources have direct knowledge of the matter and whether it is not merely a matter of settling personal scores or an attempt to gain some advantage. Such information may be true, but if its disclosure is motivated by human animosity, journalists have a greater duty to verify the information. Sometimes the media also have to trust a source which is unknown because they fear their lives, for example, because they live in a country with a repressive regime.

(4) The status of the information, especially regarding whether it is provided by a bearer of public power or authority,

(5) The steps taken to verify the information,

(6) The urgency of the matter,

(7) The address of the person being referred to (such an approach may not always be slavishly required, as the person may avoid comment, or it may be obvious that they have nothing to add to the matter. It is, therefore, a question of the fairness of the journalists' approach to The persons they report on).

(8) The presentation of the opinion of the person being reported on,

(9) The overall tone of the report, particularly since information should not be exaggerated or artificially sensationalized in the news, that speculation and rumor should not be passed off as fact, and that guilt should not be presumed.

(10) The circumstances of the publication of the report, including the timing. 
The actions of journalists must also be considered in the context of their post-publication actions, that is, whether they correct an error, explain the matter, or apologize ${ }^{19}$.

\section{Conclusion}

For a long time, the idea has been that the Internet is an extra-legem environment and that it is, therefore, a kind of shield against legal and ethical regulations. However, acting in cyberspace is not different from acting in other media. There is no reason why cyberspace should be immunized from traditional regulations. However, the difference from other media is obvious and undeniable.

Digital media can then be defined as search engines, news and discussion sites, and other portals. Their special legal regulations do not stem from the uniqueness of these media, but only from the particularity of information transmission technology. It would be fair to impose the same requirements on traditional media.

Reporting on social media cannot be a purely neutral process because it is not in human power to eliminate certain biases and prejudices. Therefore, absolute objectivity cannot be achieved because the selection of the facts to be reported is itself a biased process. That is why today, balance, conscious disinterest, and healthy skepticism are emphasized $^{20}$.

The speed of social media places great demands on media, which often cannot even verify the information disseminated in terms of its truthfulness, completeness, objectivity, and balance. Indeed, the news is a perishable commodity, and delays in publication can reduce its value and interest. Therefore, a certain amount of misrepresentation caused by the speed of news must be allowed, and some exaggeration or provocation is permissible.

However, the aforemntioned ethical standards must be enforced to prevent digital media from becoming a digital sewer. 


\section{Bibliography}

I Burton, G., Jirák, J. (2001) Úvod do studia médií. ${ }^{\text {st }}$ Brno: Barrister \& Principal.

I Crone, T. (2002) Law and the Media. Oxford: Linacre House.

Drgonec, J. (2013) SFreedom of expression and freedom after expression Šamorín: Heuréka,

McLuhan, M. (2003) Understanding Media: The Extensions of Man. Corte Madera: Gingko Press, Incorporated.

I Pember, D. (2001) Mass Media Law. New York: McGraw-Hill.

Rozehnal, A. (2008) Protection of Personality in the Media. In Bystřický, J. and collective (eds.) Media, Communication and Culture. Pilsen: Aleš Čeněk Publishing House.

I Rozehnal, A. (2015) Media Law. Pilsen: Aleš Čeněk Publishing House.

I Rozehnal, A. (2020) Media Law in the Czech Republic. Kluwer Law International.

I Weiler, P. (2002) Entertainment, Media, and the Law. St. Paul: West Group. 